\title{
Formulation and evaluation of a hydrophobic composite plastic
}

\author{
R. G. CRAIG and T. K. WANG University of Michigan, \\ School of Dentistry, Ann Arbor, Michigan, U.S.A.
}

\section{Summary}

A hydrophobic co-polymer, heptafluorobutylmethacrylate co-para vinyl phenol, was compounded with ethylene glycol dimethacrylate and silanated quartz to produce a hydrophobic composite. The experimental composite had satisfactory working properties and had mechanical properties comparable to commercial composite but a higher modulus of resilience. The wear resistance was equal to or greater than the commercial composite depending on whether a two-body abrasion test or a track width versus normal load test was used for the evaluation. The thermal coefficient of expansion and water sorption values were somewhat higher than those of commercial composites.

\section{Introduction}

Current commercial composite restorative materials are composed mainly of bis-GMA and about $70-80 \%$ by weight of silanated inorganic materials and free radical polymerization of the bis-GMA may be initiated by ultraviolet light or by a peroxide catalyst and an amine accelerator (Craig \& Peyton, 1975). Previous studies (Bowen, 1963, 1966a, 1966b; Chang, Dahlman \& Rueb, 1965; Hollenback, Villany \& Shell, 1966; Peterson, Phillips \& Swartz, 1966; Bowen, Barton \& Mulleneaux, 1969; Freeman, 1969; Gotfredsen, 1969; Macchi \& Craig, 1969; McLean \& Short, 1969; Auvenshire \& Eames, 1970; Dennison \& Craig, 1972) showed that these bis-GMA based composite materials have improved physical and mechanical properties compared to unfilled acrylic materials. The current commercial composite materials, however, do not chemically bond to tooth structure to any significant degree and restorations of these materials do not prevent marginal penetration of bacteria-containing oral fluids.

O'Brien, Craig \& Peyton (1968) established that the driving force for the capillary penetration of the oral fluids between the restorative material and the tooth structure was a function of the free energy changes at the solid-liquid interfaces and can be expressed by the following equation:

$$
\left(\mathrm{F}_{\mathrm{S}_{1} \mathrm{~V}}-\mathrm{F}_{\mathrm{S}_{1} \mathrm{~L}}\right)+\left(\mathrm{F}_{\mathrm{S}_{2} \mathrm{~V}}-\mathrm{F}_{\mathrm{S}_{2} \mathrm{~L}}\right)=-\Delta \mathrm{F}^{\mathrm{S}}=\gamma_{\mathrm{LV}}\left(\cos \theta_{1}+\cos \theta_{2}\right)
$$

Correspondence: Dr R.G. Craig, Department of Dental Materials, University of Michigan, School of Dentistry, Ann Arbor, Michigan 48109, U.S.A.

$$
\text { 0305-182X/80/0900-0361 \$02.00 } \quad \text { (C) } 1980 \text { Blackwell Scientific Publications }
$$


where $\mathrm{F}$ is the free energy, $\mathrm{S}_{1}$ and $\mathrm{S}_{2}$ are the tooth and the restorative material respectively, $\mathrm{V}$ and $\mathrm{L}$ are the vapour and the liquid, $\gamma_{\mathrm{LV}}{ }^{0}$ is the surface energy of the saliva, and $\theta_{1}$ and $\theta_{2}$ are the contact angles of the saliva against the tooth structure and the restorative material, respectively.

If $\Delta F^{\mathrm{S}}$ is negative, penetration will be spontaneous and if positive, it will not be spontaneous. In order for $\Delta F^{\mathrm{s}}$ to be positive, using $\theta_{1}=55^{\circ}$ (O'Brien et al., 1969) for enamel, and $\gamma_{\mathrm{LV}}{ }^{0}=71 \mathrm{ergs} / \mathrm{cm}^{2}$ (O'Brien, 1967) for saliva, a composite with a contact angle of greater than $143^{\circ}$ would be required. A lower contact angle on the composite would also be satisfactory if the tooth surface could be treated to give a higher contact angle.

Fluorinated acrylic polymer surfaces are known to be highly hydrophobic. A number of workers (Bernett \& Zisman, 1962; Tamaribuchi, 1967; Pittman, Sharp \& Ludwig, 1968; Roitman \& Pittman, 1972) have studied the wettability of fluorinated acrylates and methacrylates and their polymers utilizing the critical surface tension which can be determined from contact angle and surface tension measurements. Their results indicated that fluorine-containing acrylic polymers were difficult to wet with aqueous solutions. Pittman et al. (1968) found that the lowest critical surface tension for polymeric materials was $10.4 \mathrm{dyn} / \mathrm{cm}$ for pentadecafluorooctyl acrylate. This hydrophobic quality could provide a means of eliminating capillary penetration of oral fluids at the margins of dental restoration derived from a fluorinated acrylic polymer.

The objective of this study was to investigate the possibility of utilizing some newly synthesized hydrophobic fluorine-containing polymers (Overberger \& Sincich, 1975) as the matrix phase for a new composite restorative system. The formulation and evaluation of a composite restorative system based on poly(heptafluorobutyl methacrylate-co-p-vinylphenol) will be presented. The presence of the fluorinated side chains and the unsaturated groups of the polymer and the aromatic ring on the side chain could add mechanical strength. Moreover, the ductility and the abrasion resistance of the resulting composite could also be increased by the presence of the fluorinated side chains in the copolymer.

\section{Materials and methods}

\section{Preparation and evaluation of poly (heptafluorobutyl methacrylate-co-p-vinylphenol) (HFBM-co-p-VP)}

The materials, polymerization methods, and characterization procedures for the polymer were discussed in detail by Overberger \& Sincich (1975). The general formula for the copolymer is presented in Fig. 1. A co-polymer with an acrylic to phenol ratio of 240:1 was prepared. The polymerization conditions for the co-polymer are summarized in Table 1. The hydrophobic quality of the surface of HFBM-co-p-VP was evaluated from the contact angle using the inclined plane method (MacDougall \& Ockrent, 1941). The clean surface of the co-polymer for contact angle measurement was prepared by dissolving the copolymer in analytical reagent grade acetone and then pouring the solution onto a microscope slide. The slide was dried in an oven at $70^{\circ} \mathrm{C}$ for $1 \mathrm{~h}$ so that all the acetone was evaporated and a clean, flat film of the polymer was deposited. Using the methods developed by O'Brien et al. (1968), the advancing contact angles, $\theta_{\mathrm{A}}$, and the receding contact angles, $\theta_{\mathbf{R}}$, were recorded directly. Five individual measurements were made at $22^{\circ} \mathrm{C}$ and approximately $50 \%$ relative humidity. 


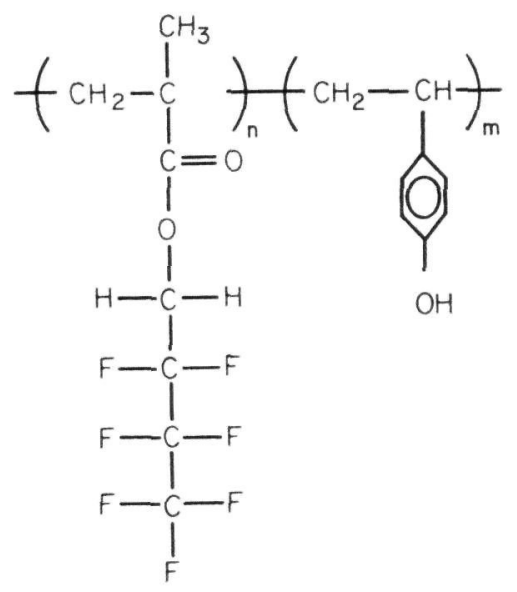

Fig. 1. Poly (heptafluorobutylmethacrylate-co-p-vinyl phenol).

Table 1. Co-polymerization of HFBM and p-vinylphenol

\begin{tabular}{rrrrrrr}
\hline $\begin{array}{r}\text { HFBM :p-Vinylphenol } \\
\text { (by weight) }\end{array}$ & AIBM $^{*}(\mathrm{~g})$ & $\operatorname{Temp}\left({ }^{\circ} \mathrm{C}\right)$ & $\begin{array}{r}\text { Polymer } \\
\text { time }(\mathrm{h})\end{array}$ & Yield $(\%)$ & $\theta_{\mathrm{A}}$ (degrees) & $\theta_{\mathrm{R}}$ (degrees) \\
\hline $240=1$ & 0.01584 & 70 & 18 & 80.52 & $105(2) \dagger$ & $83(2) \dagger$ \\
\hline
\end{tabular}

* Azobisisobutyronitrile; † values in parentheses are standard deviations.

Formulation of the composite

The composition of the experimental composite is given in Table 2. Manufacturers and batch numbers of the chemicals used are listed in the footnotes to the table. Ethylene glycol dimethacrylate was used as the difunctional monomer for crosslinking with HFBM-co-p-VP. Benzoyl peroxide and N,N-dimethyl-p-toluidine were used as the initiator and the accelerator, respectively.

Table 2. Composition of experimental composite

\begin{tabular}{lr}
\hline Ingredients & $\%$ by weight \\
\hline Silanated quartz & $71 \cdot 27$ \\
HFBM-co-p-VP & $7 \cdot 92$ \\
Benzoyl peroxide & $0 \cdot 32$ \\
N,N-dimethyl-p-toluidine & 0.28 \\
Ethylene glycol dimethacrylate & $20 \cdot 21$ \\
\hline
\end{tabular}

* Supplied by $3 \mathrm{M}$ Company, St Paul, Minnesota, U.S.A.

Measured amounts of silanated quartz, polymer and ethylene glycol dimethacrylate were mixed thoroughly. The paste was then divided into two equal parts. The premeasured benzoyl peroxide and the monomer/accelerator solution were added separately to the pastes to make a two-paste restorative system.

\section{Evaluation of the composite}

The amount of inorganic phase present in the composite, the polymerization contraction, indentation resistance and recovery, compressive strength, $0.1 \%$ yield strength, modulus of elasticity, and modulus of resilience were determined according to the 
methods used by Macchi \& Craig (1969). The method employed by Powers, Allen \& Craig (1974) was used for the two-body abrasion test and track width versus load values were measured according to the method of Powers, Roberts \& Craig (1976). Water sorption and solubility were determined according to the methods by Dennison \& Craig (1972).

The working time of the composite was determined according to American Dental Association Specification No. 27 for direct filling resins (Council on Dental Materials and Devices, 1977). The working time was reported to the nearest minute and was the average of five determinations.

Density of the experimental composite was determined by Archimedes' buoyancy technique as described in ASTM Specification D 792 (1968). The reported value was the average of five determinations.

The average thermal coefficient of expansion of the composite between $0^{\circ}$ and $60^{\circ} \mathrm{C}$ was determined using a thermomechanical analyzer*. The $8 \mathrm{~mm}$ long by $3.5 \mathrm{~mm}$ diameter specimens were preconditioned in distilled water at $37^{\circ} \mathrm{C}$ for $24 \mathrm{~h}$. Five individual determinations were made for the composite.

The inclined plane method (MacDougall \& Ockrent, 1941) was used to determine the contact angles of distilled water on the composite surface. A flat surface of the experimental composite resin was prepared by mixing the two pastes together and by putting the unset resin between a Mylar sheet and a microscope slide. A clean flat surface of the composite resin could be obtained by peeling off the Mylar sheet after the resin had set. For the experimental composite, the surface was then polished with 600 -grit silicon carbide paper to remove the excessive dimethacrylate layer. Using the same method as for the contact angle measurements on the polymer, five individual measurements were made for the composite at $22^{\circ} \mathrm{C}$ and at approximately $50 \%$ relative humidity.

The Charpy type impact test was used to determine the impact resistance of the experimental composite material. Five un-notched specimens $4 \times 0.2 \times 0.2 \mathrm{~cm}$ were prepared in split stainless steel dies and were preconditioned in distilled water at $37^{\circ} \mathrm{C}$ for $24 \mathrm{~h}$.

\section{Results}

The co-polymer of heptafluorobutylmethacrylate and p-vinyl phenol was highly hydrophobic as shown by the high advancing contact angle with water of $105^{\circ} \mathrm{C}$ (Table 1).

The physical properties of the composite prepared according to the formulation given in Table 2 are listed in Table 3. The physical properties of the experimental composites were similar to the commercial composites except that the thermal coefficient of expansion was about $25 \%$ higher and the contact angles were higher. The advancing angle of the experimental composite was lower than for the copolymer alone although it was still hydrophobic with an angle of greater than 90 degrees. The physical properties of an unfilled acrylic, Sevriton, are listed for purposes of comparison.

The mechanical properties of the experimental composite are compared with commercial composites and an unfilled acrylic restorative material in Table 4 . The

* duPont 941 Thermomechanical Analyzer, Instrument Products Division, E.I. duPont de Nemours and Company, Wilmington, Delaware 19898. 
Table 3. Physical characteristics of the experimental composite compared with three commercial restorative materials

\begin{tabular}{|c|c|c|c|c|}
\hline Property & $\begin{array}{r}\text { Experimental } \\
\text { composite } \\
\text { resin }\end{array}$ & Adaptic & Concise & Sevriton \\
\hline Inorganic phase $(\mathrm{wt} \%)$ & $70 \cdot 6(0 \cdot 3)$ & $77 \cdot 7(0 \cdot 2)^{*}$ & $71.9(0.1)^{*}$ & $\longrightarrow$ \\
\hline Working time (min) & $2 \cdot 6(0 \cdot 4)$ & $3 \cdot 5(0 \cdot 3)^{*}$ & $3 \cdot 0(0)^{*}$ & $4.0(0.5) \dagger$ \\
\hline Polymerization contraction (vol. $\%$ ) & $1 \cdot 8(0 \cdot 2)$ & $1 \cdot 3(0 \cdot 1)^{*}$ & $1 \cdot 6(0 \cdot 2)^{*}$ & $5 \cdot 2(0.5) \dagger$ \\
\hline Density $(\mathrm{g} / \mathrm{ml})$ & $1.96(0.03)$ & $1.98(0.01)^{*}$ & $1.77(0.03)^{*}$ & $1.12(0.02) \dagger$ \\
\hline $\begin{array}{l}\text { Thermal coefficient of expansion } \\
\left({ }^{\circ} \mathrm{C} \times 10^{-6}\right)\end{array}$ & $48 \cdot 0(5 \cdot 9)$ & $39 \cdot 4(1 \cdot 4)^{*}$ & $37 \cdot 3(0 \cdot 2)^{*}$ & $92 \cdot 0(2 \cdot 3) \dagger$ \\
\hline Advancing angle, $\theta_{\mathrm{A}}$ (degrees) & $92(2) \div$ & $64(1)$ & $62(1)$ & $61(2)$ \\
\hline Receding angle, $\theta_{R}$ (degrees) & $61(2) \ddagger$ & $48 \cdot 5(0 \cdot 5)$ & $44(2)$ & $38(3)$ \\
\hline
\end{tabular}

* Data from Dennison \& Craig (1972).

$\dagger$ Data from Macchi \& Craig (1969).

\$Contact angle of samples finished with 600 grit silicon carbide; for unfinished samples, the mean $\theta_{\mathrm{A}}=64^{\circ}(1)$, and $\theta_{\mathrm{R}}=46(2)$.

Values with the same underlining indicate nonstatistically significant differences, and values in parentheses are standard deviations. The multiple range test at the $95 \%$ level of confidence was used (Duncan, 1955).

Table 4. Mechanical properties of the experimental composite resin compared with three commercial restorative materials

\begin{tabular}{|c|c|c|c|c|}
\hline Property & $\begin{array}{r}\text { Experimental } \\
\text { composite } \\
\text { resin }\end{array}$ & Adaptic & Concise & Sevriton \\
\hline Indentation depth (mm) & $0.069(0.003)$ & $0.061(0 \cdot 002)$ & $0.060(0 \cdot 002)$ & $0 \cdot 113(0 \cdot 003)$ \\
\hline Recovery $(\%)$ & $82 \cdot 5(3 \cdot 5)$ & $74.9(1.7)^{*}$ & $82.8(1.7)^{*}$ & $74 \cdot 1(3 \cdot 5) \dagger$ \\
\hline Compressive strength (MPa) & $184(22)$ & $237(21)^{*}$ & $215(7)^{*}$ & $71(14)$ \\
\hline $0.1 \%$ yield strength $(\mathrm{MPa})$ & $158(24)$ & $161(9)^{*}$ & $142(14)^{*}$ & $52(7)^{*}$ \\
\hline Modulus of elasticity $\left(\mathrm{MPa} \times 10^{4}\right)$ & $0 \cdot 78(0 \cdot 15)$ & $1.66(0.09)^{*}$ & $1 \cdot 17(0 \cdot 17)^{*}$ & $0.23(0.05) \dagger$ \\
\hline Modulus of resilience $(\mathrm{mMPa} / \mathrm{m})$ & $1.37(0.59)$ & $0 \cdot 78(0 \cdot 05)^{*}$ & $0.87(0 \cdot 19)^{*}$ & $0 \cdot 62(0 \cdot 20) \dagger$ \\
\hline Tensile strength (MPa) & $30 \cdot 8(3 \cdot 6)$ & $45 \cdot 5(2 \cdot 4)^{*}$ & $35 \cdot 2(4 \cdot 8)^{*}$ & $22 \cdot 8(0 \cdot 7) \dagger$ \\
\hline Impact resistance $(\mathrm{N}-\mathrm{m})$ & $0.07(0.01)$ & - & $0 \cdot 18(0.05)$ & $0 \cdot 11(0 \cdot 04)$ \\
\hline $\begin{array}{l}\text { Abrasive wear } \\
\qquad\left(\mathrm{mm}^{3} / \mathrm{mm} \text { of travel } \times 10^{-4}\right)\end{array}$ & $4 \cdot 3(0 \cdot 5)$ & $3 \cdot 8(0 \cdot 2) \div$ & $4 \cdot 1(0 \cdot 9) \ddagger$ & $13 \cdot 3(1 \cdot 6) \ddagger$ \\
\hline
\end{tabular}

* Data from Dennison \& Craig (1972).

$\dagger$ Data from Macchi \& Craig (1969).

$¥$ Data from Powers, Allen \& Craig (1974).

Values with the same underlining indicate nonstatistically significant differences; those in parentheses are standard deviations. The multiple range test at the $95 \%$ level of confidence was used (Duncan 1955).

mechanical properties of the experimental composite were comparable to the commercial composites except that the compressive strength and modulus of elasticity 
Table 5. Water sorption and solubility of the experimental composite and three commercial restorative materials

\begin{tabular}{|c|c|c|c|c|}
\hline Procedure & $\begin{array}{r}\text { Experimental } \\
\text { composite }\end{array}$ & Adaptic & Concise & Sevriton \\
\hline \multicolumn{5}{|c|}{ Water sorption $\left(\mathrm{mg} / \mathrm{cm}^{2}\right)$} \\
\hline $24 \mathrm{~h}$ & $1.02(0.11)$ & $0.37(0.07)$ & $0 \cdot 13(0.03)$ & $1.58(0.27)$ \\
\hline $48 \mathrm{~h}$ & $\overline{1.05(0 \cdot 16)}$ & $0.42(0.04)$ & $0 \cdot 15(0 \cdot 01)$ & $\overline{1.67(0.22)}$ \\
\hline 7 days & $1 \cdot 11(0 \cdot 16)$ & $0.59(0.02)$ & $0 \cdot 20(0 \cdot 02)$ & $2 \cdot 03(0 \cdot 30)$ \\
\hline 14 days & $1 \cdot 11(0 \cdot 16)$ & $0.66(0.04)$ & $0.25(0.03)$ & $2 \cdot 08(0 \cdot 29)$ \\
\hline \multicolumn{5}{|c|}{ Solubility $(\%)$} \\
\hline 14 days & $0 \cdot 11(0 \cdot 02)$ & $<0 \cdot 01$ & $<0.01$ & $0.23(0.03)$ \\
\hline
\end{tabular}

Values with same underlining indicate nonstatistically significant differences, those in parentheses are standard deviation. The multiple range test at the $95 \%$ level of confidence was used (Duncan 1955).

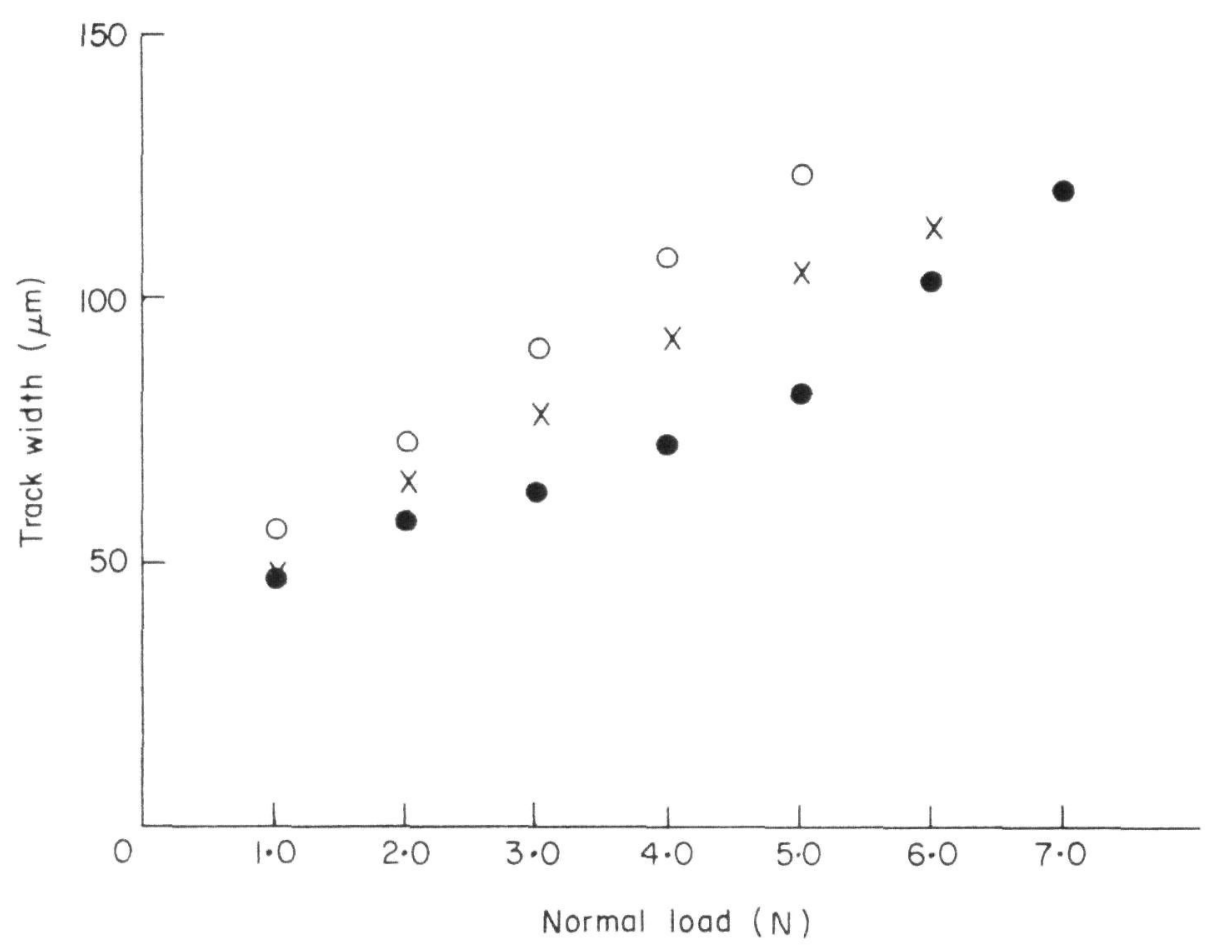

Fig. 2. Width of the wear track versus normal load for the experimental composite and two commercial composites. $(\bullet)$ experimental composites; $(\mathbf{X})$ Adaptic; $(\bigcirc)$ Smile.

were about 20 and $40 \%$ lower, respectively and the modulus of resiliency was about $40 \%$ higher.

The water sorption and solubility values of the experimental composite, two commercial composites and an unfilled acrylic restorative are listed in Table 5. The sorption and solubility of the experimental composite was intermediate to the commercial composites and the unfilled acrylic.

The average values of the wear track width versus normal load are shown for the experimental composite and two commercial composites in Fig. 2. The track width for the experimental composite was consistently less than for the commercial composites. Smile which has a glass rather than a quartz filler had the highest values for track width. 


\section{Discussion}

The higher thermal coefficient of expansion of the experimental composite compared with the commercial composites is probably related to a higher residual monomer content as suggested by the water solubility values. Marginal leakage resulting from the mismatch of the thermal coefficient of expansion of the hydrophobic experimental composite and the tooth structure should be less important than for the hydrophilic commercial composites since the hydrophobic nature of the composite should restrict penetration of fluids because of the contact angle.

The hydrophobic quality of the experimental composite should be increased if the glycol dimethacrylate crosslinking agent were replaced by a fluorinated crosslinking agent and if the coupling agent for the quartz filler were a fluorinated vinyl silane.

The lower compressive strength and modulus of the experimental composite compared with the commercial composites certainly indicate that it could be used only in non-stress bearing areas. In spite of these lower values the abrasive wear rate was not different than the commercial composites and the modulus of resilience was greater. This latter value indicates that the experimental composite can absorb more energy under static loading before permanent deformation would occur.

Although the wear rate by the two-body abrasion test did not show any difference between the experimental and commercial composites, the track width versus normal load curves showed that the experimental composite was superior to Adaptic and Smile. Results of studies by Powers et al. (1976) and Roberts, Powers \& Craig (1977) indicate that the width of the wear track is a better predictor of wear resistance than the twobody abrasion test because of the severity of the latter test. Thus, it would appear that the experimental composite may be superior to the commercial composite, probably because of its increased ductility and modulus of resilience.

The higher water sorption and solubility of the experimental composite was unexpected because of the hydrophobic qualities. These results may have been caused by residual unreacted as well as reacted glycol dimethacrylate which will absorb water. Also, the silane treated quartz is still hydrophilic and a more hydrophobic treated quartz might be more compatible with the hydrophobic polymer phase and reduce the water sorption and solubility.

\section{Acknowledgment}

This study was supported by USPHS Grant DE-04050 from the National Institute of Dental Research, National Institutes of Health, Bethesda, Md.

\section{References}

ASTM StAndards PART 27 (1968) Standard methods of test for specific gravity and density of plastics by displacement, ASTM designation: D-792-66.

Auvenshine, R.C. \& Eames, W.B. (1970) Dimensional changes during the first ten minutes of setting in eight restorative materials. Microfilm Dental Materials Group Papers, IADR Meeting, New York City, Paper No. 409.

Bernett, M.K. \& Zisman, W.A. (1962) Wetting properties of acrylic and methacrylic polymers containing fluorinated side chains. Journal of Physical Chemistry, 66, 1207.

Bowen, R.L. (1963) Properties of a silica-reinforced polymer for dental restoration. Journal of American Dental Association, 66, 57.

BowEN, R.L. (1964) Effect of particle shape and size distribution in a reinforced polymer. Journal of American Dental Association, 69, 481.

Bowen, R.L. (1966) Inorganic fillers for resin composites, IADR Program and Abstracts of Papers, $2,37$. 
Bowen, R.L., Barton, J.A., JR \& Mullineaux, A.L. (1969) Composite restorative materials. In: Dental Materials Research. Proceedings of the 50th Anniversary Symposium (Ed. by G. Dickson and J.M. Cassel), p. 93. National Bureau of Standards, Gaithersburg.

Chang, R.W.H., Dahlman, K.E. \& Rueb, J.T. (1965) Properties of a composite material for dental filling. Microfilm Dental Materials Group Papers, IADR Meeting, Toronto, Canada, 29.

Council on Dental Materials and Devices (1977) New American Dental Association specification No. 27 for direct filling resins. Journal of American Dental Association, 94, 1191.

Craig, R.G., \& Peyton, F.A. (1975) Restorative dental materials, 5th edn, p. 433. Mosby, St Louis.

Dennison, J.B. \& Craig, R.G. (1972) Physical properties and finished surface texture of composite restorative resins. Journal of American Dental Association, 85, 101.

DunCan, D.B. (1955) Multiple range and multiple F tests. Biometrics, 11, 1.

Freeman, F.H. (1969) Composite restorative materials. Microfilm Dental Materials Group Papers, IADR Meeting, Houston, Texas, 146.

Gotfredsen, C. (1969) Physical properties of a plastic filling material (Addent). Acta odontologica scandinavica, 27, 595.

Hollenback, G.M., Villany, A.A. \& Shell, J.S. (1966) A report on the physical properties of a new restorative material (Addent). Journal of Southern California State Dental Hygienists Associa:ion, 34, 250.

Macchi, R.L. \& Craig, R.G. (1969) Physical and mechanical properties of composite restorative materials. Journal of American Dental Association, 78, 338.

MacDougall, G. \& Ockrent, C. (1941) Surface energy relations in liquid solid system. Proceedings of Royal Society London, 180A, 151.

MCLean, J.W. \& Short, I.G. (1969) Composite anterior filling materials, a clinical and physical appraisal, British Dental Journal, 127, 9.

O'Brien, W.J. (1967) Capillary penetration of liquids between dissimilar solids. Ph.D. Dissertation, University of Michigan, Ann Arbor.

O'Brien, W.J., Craig, R.G. \& Peyton, F.A. (1968) Capillary penetration between dissimilar solids. Journal of Colloid and Interface Science, 26, 500.

O'Brien, W.J., Martinex, N.P., Rysiejko, M. \& Craig, R.G. (1969) Contact angles of water and saliva on dental amalgams and treated tooth structure. IADR Program and Abstracts of Papers, 238, p. 100.

Overberger, C.G. \& Sincich, E. (1975) Copolymerization of fluorinated acrylic monomers with p-vinyl phenol and hydroxyethyl methacrylate. Journal of Polymer Science, A-1 13, 1783.

Peterson, E.A., II, Phillips, R.W. \& Swartz, M.L. (1966) A comparison of the physical properties of four restorative resins. Journal of American Dental Association, 73, 1324.

Pittman, A.G., Sharp, D.L. \& Ludwig, B.A. (1968) Polymers derived from fluorokeytones. II. Wetting properties of fluoroalkyl acrylates and methacrylates. Journal of Polymer Science, A-1 6, 1729 .

Powers, J.M., Allen, L.J. \& Craig, R.G. (1974) Two-body abrasion of commercial and experimental restorative and coating resins and an amalgam. Journal of American Dental Association, 89, 1118.

Powers, J.M., Roberts, J.C. \& Craig, R.G. (1976) Surface failure of commercial and experimental restorative resins. Journal of Dental Research, 55, 432.

Roberts, J.C., Powers, J.M., \& Craig, R.G. (1977) Wear of commercial pit and fissure sealants. Journal of Dental Research, 56, 692.

Roitman, J.N. \& Pittman, A.G. (1972) Wetting properties of acrylic containing perfluoro-t-butyl side chains. Journal of Polymer Science, B, 10, 499.

TAmaribuchi, K. (1967) Wettability of styrene-2, 2, 3-tetrafluoropropyl methacrylate copolymers. American Chemical Society Polymer Preprints, 8, 631.

\section{Manuscript accepted 14 August 1978}


This document is a scanned copy of a printed document. No warranty is given about the accuracy of the copy. Users should refer to the original published version of the material. 